\title{
Molecular identification of Borrelia spirochetes in questing Ixodes ricinus from northwestern Spain
}

\author{
Pablo Díaz ${ }^{1 *}$, Jose Luis Arnal ${ }^{2}$, Susana Remesar ${ }^{1}$, Ana Pérez-Creo ${ }^{1}$, José Manuel Venzal ${ }^{3}$,

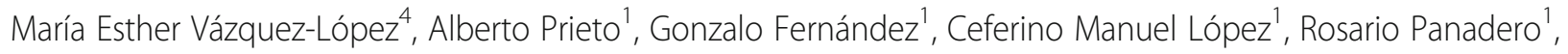 \\ Alfredo Benito ${ }^{2}$, Pablo Díez-Baños ${ }^{1}$ and Patrocinio Morrondo ${ }^{1}$
}

\begin{abstract}
Background: Ixodes ricinus, the predominant tick species in Europe, can transmit the causative agents of important human diseases such as Lyme borreliosis (LB), caused by Borrelia spirochetes. In northern Spain, LB is considered endemic; recently, a significant increase of the annual incidence of $L B$ was reported in the northwestern (NW) region.

Methods: In order to provide information on the prevalence of Borrelia spp., pooled and individually free-living I. ricinus from NW Spain were molecularly analyzed. Positive samples were characterized at the fla and Glpq genes and the rrfA-rrlB intergenic spacer region to identify Borrelia species/genospecies.

Results: Borrelia burgdorferi (sensu lato) (s.l.) individual prevalence and MIR were significantly higher in adult females (32.3 and 16\%) than in nymphs (18.8 and 6.2\%) and adult males (15.6 and 8.4\%). Five Borrelia genospecies belonging to the $B$. burgdorferi (s.l.) group were identified: B. garinii was predominant, followed by B. valaisiana, B. lusitaniae, B. afzelii and B. burgdorferi (sensu stricto) (s.s.). One species belonging to the tick-borne relapsing fever group (B. miyamotoi) was also found, showing low individual prevalence (1\%), positive pool $(0.7 \%)$ and MIR $(0.1 \%)$ values. To our knowledge, this is the first citation of B. miyamotoi in free-living ticks from Spain.
\end{abstract}

Conclusions: The significant prevalences of B. burgdorferi (s.l.) genospecies detected in questing ticks from NW Spain are similar to those detected in northern and central European countries and higher to those previously found in Spain. These results together with the high incidence of $L B$ in humans and the high seroprevalence of $B$. burgdorferi (s.l.) in roe deer shown in other studies reveal that the northwest area is one of the most risky regions for acquiring $L B$ in Spain.

Keywords: Borrelia burgdorferi (s.I.), Borrelia miyamotoi, Ixodes ricinus, NW Spain

\section{Background}

Ixodes ricinus is considered the tick species with the widest distribution in Europe, transmitting the causative agents of important human and animal diseases; Borrelia spp. are amongst the most commonly identified pathogens in I. ricinus [1]. These spirochetes are clustered into three major phylogenetic groups, namely the Lyme borreliosis (LB) group, the relapsing fever (TBRF) group and the reptile-associated borreliae [2].

\footnotetext{
* Correspondence: pablo.diaz@usc.es

'Departamento de Patología Animal (Grupo INVESAGA), Facultad de Veterinaria, Universidade de Santiago de Compostela, Lugo, Spain

Full list of author information is available at the end of the article
}

LB is caused by Borrelia burgdorferi (sensu lato) (s.l.); more than 20 Borrelia genospecies have been currently identified within the B. burgdorferi (s.l.) species complex. In Europe, LB is mainly caused by three genospecies: Borrelia garinii, associated with neuroborreliosis; Borrelia afzelii related to atrophic chronic acrodermatitis; and Borrelia burgdorferi (sensu stricto) (s.s.) related to arthritis [3]. Borrelia bavariensis, Borrelia bissettii, Borrelia lusitaniae and Borrelia spielmanii have been also identified as causal agents of LB in this continent [4]. Phylogenetically related to relapsing fever spirochetes, Borrelia miyamotoi has been generally identified worldwide in the same Ixodes species as B. burgdorferi (s.l.) [5, 6]. Although it was initially considered as non-pathogenic for people, 
human cases of B. miyamotoi disease (BMD), very different to relapsing fever cases, have recently been reported in the USA, the Netherlands, Russia and Japan [5, 7].

Twenty-four years ago, the overall annual incidence of LB in Spain was estimated to be 0.25 cases per 100,000 inhabitants although the disease is especially common in the northern regions where it is considered endemic [8]. In contrast, the endemic form of the TBRF has been diagnosed in central and southern regions, presenting a lower annual incidence $(0.2 / 100,000$ inhabitants) than LB $[9,10]$. In Galicia (NW Spain), an increase of the annual incidence of LB was reported in recent years [11]. In addition, it was determined that roe deer from this region were highly exposed to B. burgdorferi (s.l.) [12]. However, currently no studies have been performed on the percentage of infection and molecular identification of Borrelia spp. isolated from ticks in NW Spain. The main aim of the present study was to identify the species/genospecies of LB and TBRF Borrelia in free-living I. ricinus from Galicia (NW Spain) and to provide information on their prevalence.

\section{Methods}

\section{Study area}

The study was performed in Galicia, a $29,574 \mathrm{~km}^{2}$ region located in the northwest of Spain $\left(43^{\circ} 47^{\prime}-41^{\circ} 49^{\prime} \mathrm{N}, 6^{\circ}\right.$ $\left.42^{\prime}-9^{\circ} 18^{\prime} \mathrm{W}\right)$ with an oceanic climate, characterized by mild temperatures and high precipitation. Galicia is a major livestock breeding area, where animals are mainly reared in a semi-extensive management system; the landscape is composed of meadows (Poa pratensis, Lolium perenne and Festuca pratensis) and large autochthonous forest areas, the more common tree species being Quercus robur and Castanea sativa [13].

\section{Collection of ticks}

In 2015, questing ticks were collected by flagging from vegetation in 17 different sampling locations. A $1 \mathrm{~m}^{2}$ piece of white cotton flannel was used and the ticks on the flag were counted and removed every $2 \mathrm{~m}$. The flagging time (30 min of sampling) was similar in each site. Ticks were conserved in $90 \%$ ethanol until analyzed. In the laboratory, ticks were examined microscopically and identified to stage and species using different reference keys [14, 15].

Pools of ten whole $I$. ricinus nymphs or up to five adults from each sampling location were first analyzed in order to detect Borrelia spp. Data for the number of pools and ticks processed are summarized in Table 1. Initially, ticks were washed in sterile distilled water. Then, adult ticks were longitudinally cut with a sterile scalpel, and half only was used; the whole nymphs were processed. Finally DNA was extracted using a commercial kit (High Pure PCR Template Preparation Kit, Roche Diagnostics $\mathrm{GmbH}^{\circ}$, Mannheim, Germany) following the manufacturer's instructions. In order to maximize DNA yields, ticks were first crushed with a micropestle in $200 \mu \mathrm{l}$ of Tissue Lysis Buffer. All tick pools were subjected to a nested PCR targeting the fla gene, using previously described protocols $[16,17]$.

In addition, the presence of Borrelia spp. DNA was determined from 384 (192 nymphs, 96 males and 96 females) individual $I$. ricinus samples by a real-time PCR assay. Adults and nymphs were processed and DNA extracted using the same protocol as for pool analysis. A qPCR targeting the flagellin gene $(f l a)$, especially developed for the present study, was designed manually based on multiple sequence alignment as follows: forward (5'GCT CAA TAT AAC CAA ATG CAC ATG-3'), reverse (5'-AGA TTT GCA ACA TTA GCT GCA TAA A-3') and probe $\left(5^{\prime}\right.$-156-FAM/AAC AGC TGA AGA GCT TGG AAT GCA/3IABkFQ/-3'). The qPCR was performed using $5 \mu \mathrm{l}$ of template into a $20 \mu \mathrm{l}$ reaction final volume using GoTaq $^{\text {tm }}$ Master Mix (Promega, Madison, WI, USA) on a 7500 FAST cycler (Applied Biosystems, Foster City, CA, USA) under the following conditions: initial denaturation at $95{ }^{\circ} \mathrm{C}$ for $5 \mathrm{~min}, 40$ cycles of denaturation at $95{ }^{\circ} \mathrm{C}$ for $15 \mathrm{~s}$ and annealing and extension

Table 1 Percentage of Borrelia burgdorferi (s.l.) and relapsing fever Borrelia positive individual ticks and pools, and minimum infection rate (MIR) in questing I. ricinus from NW Spain

\begin{tabular}{|c|c|c|c|}
\hline & & Borrelia burgdorferi (s.l.) & Relapsing fever Borrelia \\
\hline \multirow[t]{3}{*}{$\overline{\text { Nymphs }^{a}}$} & Positive ticks & $26 / 192(18.8 \%)$ & $2 / 192(1.0 \%)$ \\
\hline & Positive pools & 45/73 (61.6\%) & 0/73 (0) \\
\hline & MIR & 45/730 (6.2\%) & 0/730 (0) \\
\hline \multirow[t]{3}{*}{ Adult males ${ }^{b}$} & Positive ticks & 15/96 (15.6\%) & $1 / 96(1.0 \%)$ \\
\hline & Positive pools & 12/32 (37.5\%) & $1 / 32(3.1 \%)$ \\
\hline & MIR & $12 / 143(8.4 \%)$ & $1 / 143(0.7 \%)$ \\
\hline \multirow[t]{3}{*}{ Adult females ${ }^{b}$} & Positive ticks & $31 / 96$ (32.3\%) & $1 / 96(1.0 \%)$ \\
\hline & Positive pools & 28/37 (75.7\%) & $0 / 37(0)$ \\
\hline & MIR & 28/175 (16.0\%) & $0 / 175(0)$ \\
\hline
\end{tabular}


at $60{ }^{\circ} \mathrm{C}$ for $1 \mathrm{~min}$. To generate quantitative data, a synthetic oligonucleotide (Ultramer ${ }^{\mathrm{rm}}$, Integrated DNA Technologies Inc., Coralville, IO, USA) encompassing the fla region targeted by the primers was used as positive control. It was normalized at $5 \times 10^{5}$ copies per reaction and 3 replicates from its serial 10-fold dilutions were tested to obtain efficiency, linearity and repeatability data of the assay. A cut-off value for positive samples was established at cycle quantification $(\mathrm{Cq})$ values lower than 38. The inclusivity of this qPCR assay was tested analysing previously confirmed samples containing all Borrelia burgdorferi (s.l.) genospecies described in Spain [18-21]. All qPCR positive individual tick samples were also tested using the aforementioned fla nested-PCR. In order to identify Borrelia species/genospecies, PCR products were purified and subsequently sequenced; sequences were aligned and edited using ChromasPro (Technelysium, Brisbane, Australia), and consensus sequences were scanned against the GenBank database using the Basic Local Alignment Search Tool (BLAST; http://blast.ncbi.nlm.nih.gov/Blast.cgi). Finally, all individual and pooled samples identified as B. burgdorferi (s.l.) or $B$. miyamotoi were further characterized at the $\operatorname{rrfA}-\mathrm{rrl} B$ intergenic spacer region (IGS) and the glycerophosphodiester phosphodiesterase $(G l p Q)$ gene, respectively, using primers previously reported [22, 23]. Unique partial sequences identified in this study were deposited in the GenBank database under accession numbers MG245772-MG245790 and MG356949-MG356956 (Additional file 1: Table S1).

\section{Statistical analysis}

The minimum infection rate (MIR) was used to estimate the prevalence of Borrelia in pooled ticks. This was calculated as the ratio of the number of positive pools to the total number of tested ticks, assuming that only one infected tick exists in a positive pool. Differences in both the individual prevalence and MIR between nymphs, adult males and adult females were analyzed by means of a Chi-square test. All statistical analyses were performed using IBM SPSS Statistics 20 (IBM Corporation, Armonk, New York, USA).

\section{Results}

The qPCR assay obtained $93.26 \%$ of efficiency and a linearity value of $R^{2}=0.99$. Moreover, the intra-assay reproducibility test resulted in a range of values from $0.5-32.7 \%$ (Fig. 1). The lower limit of detection was established as at least 5 copies per reaction and the lower limit of quantification was 50 copies per reaction. The inclusivity test resulted in positive detection of all genospecies mentioned before. Cq values ranged from $27.22\left(5.14 \times 10^{3}\right.$ copies/reaction) to 37.87 (4.73 copies/reaction).

After fla and IGS PCRs, all positive samples were sequenced successfully, except for ten individual isolates which had underlying signals in the electropherogram that prevented the accurate readout of sequences. In both individual and pooled ticks, sequence analysis allowed the identification of four pathogenic Borrelia genospecies belonging to the B. burgdorferi (s.l.) group (B. afzelii, B. garinii, B. lusitaniae and B. valaisiana) and one belonging to the relapsing fever Borrelia group ( $B$. miyamotoi); in addition, B. burgdorferi (s.s.) was only detected in pooled samples.

The prevalence of B. burgdorferi (s.l.) and relapsing fever Borrelia in both individual and pooled ticks as well as the minimum infection rate (MIR) are summarized in

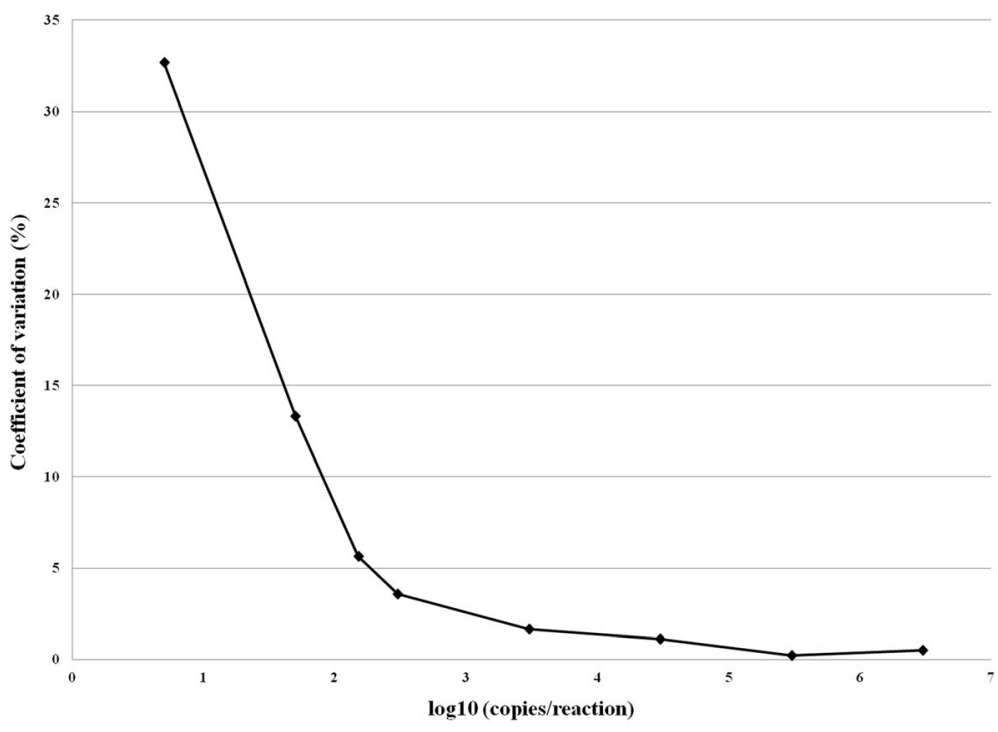

Fig. 1 Intra-assay reproducibility of the qPCR targeting the flagellin gene (fla for the detection of Borrelia spp. DNA 
Table 1. The individual prevalence of B. burgdorferi (s.l.) was significantly higher in adult females than in nymphs $\left(\chi^{2}=14.174, d f=1, P<0.001\right)$ and adult males $\left(\chi^{2}=\right.$ $7.319, d f=1, P=0.006)$. In contrast, the mean number of Borrelia spirochetes per tick was higher in adult males (1.25e 04 ; coefficient of variation $(\mathrm{CV})=2.19$; range $=$ $1.50 \mathrm{e} 05-2.17 \mathrm{e} 01)$ than in nymphs $(4.73 \mathrm{e} 03 ; \mathrm{CV}=2.67$; 5.40e04-2.46e01) and adult females $(2.83 \mathrm{e} 03, \mathrm{CV}=2.55$; 3.68e 04-5.01e01). Considering the pooled samples, the percentage of positive pools was higher in both I. ricinus adult females and nymphs than in adult males (Table 1); furthermore, MIR was significantly higher in adult females than in nymphs $\left(\chi^{2}=18.635, d f=1, P<0.001\right)$ and adult males $\left(\chi^{2}=4.143, d f=1, P=0.042\right)$.

B. miyamotoi was only identified in four individual $I$. ricinus (two nymphs, one adult male and one adult female) and in one adult male pool, showing low individual and pooled prevalence and MIR values (Table 1).

In general, amongst all the six Borrelia species/genospecies detected, $B$. garinii was the predominant genospecies, followed by $B$. valaisiana, $B$. lusitaniae and $B$. afzelii. In contrast, B. miyamotoi and B. burgdorferi (s.s.) were only occasionally found (Table 2). Considering the different tick development stages, all five Borrelia species/genospecies detected in individual samples were identified in nymphs, males and females (Table 2). In contrast, five Borrelia species/genospecies were identified in nymph pools and four in adult male pools whilst only the three most frequent genospecies (B. garinii, $B$. valaisiana and $B$. lusitaniae) were detected in adult female pools (Table 2).

\section{Discussion}

Our data revealed that B. burgdorferi (s.l.) is a very prevalent pathogen in questing $I$. ricinus from Galicia (NW Spain), with similar percentages to those recorded in some central and northern European countries [2428]. The study area presents abundant Borrelia-reservoir and $I$. ricinus-maintenance host species (micromammals, birds, roe deer, wild boars, etc.), as well as proper habitat (deciduous forests) and climatic conditions (moderate precipitation and mild temperatures throughout the year) for questing ticks. In addition, our data showed values far higher than previous individual B. burgdorferi (s.l.) prevalences found in I. ricinus from other northern Spanish regions, where the percentage of infection did not exceed 9.3\% [19, 21, 29]. This increment might be related to a recent increase in the prevalence of $B$. burgdorferi (s.l.) in free-living ticks, as recorded in some European countries in the last years $[25,30]$. In fact, a significant increase of the annual incidence of human LB was observed in the study area, from 2.64 cases $/ 100,000$ inhabitants in 2007 to 11.61 in 2012 [11]. Changes in some biotic and abiotic factors might have favoured an increase in $I$. ricinus densities and consequently in $B$. burgdorferi (s.l.) prevalence; higher average temperatures recorded in the last years in NW Spain have led to milder winters that increased both the overwintering survival and the extension of the active period of freeliving ticks and consequently extended the duration of the peak risk of exposure to tick-borne pathogens [31]. In addition, the progressive rural depopulation experienced by Galicia in recent decades has resulted in an increase of the extension of woodland areas, favouring the increase in range and abundance of Borrelia-reservoir hosts and maintenance hosts for I. ricinus [11].

Borrelia burgdorferi (s.l.) prevalence and MIR values were significantly highest in adult female ticks, which agrees with previous studies carried out in Europe [26, 32, 33]. Ixodes ricinus nymphs have a lower probability of being infected by Borrelia spp. than adults, which have ingested a supplementary potentially infected meal

Table 2 Individual prevalence and minimum infection rate (MIR) of Borrelia genospecies of Borrelia burgdorferi (s.l.) and Borrelia miyamotoi considering the life stage of questing I. ricinus collected in NW Spain

\begin{tabular}{|c|c|c|c|c|c|c|}
\hline & \multicolumn{2}{|l|}{ Nymphs } & \multicolumn{2}{|l|}{ Adult males } & \multicolumn{2}{|l|}{ Adult females } \\
\hline & Individual & MIR & Individual & MIR & Individual & MIR \\
\hline \multicolumn{7}{|c|}{ Borrelia burgdorferi (s.l.) } \\
\hline B. afzelii & 5/192 (2.6\%) & $2 / 730(0.3 \%)$ & $1 / 96(1.0 \%)$ & $1 / 143(0.7 \%)$ & $1 / 96(1.0 \%)$ & 0/175 (0) \\
\hline B. burgdorferi (s.s.) & 0/192 (0\%) & $1 / 730(0.1 \%)$ & 0/96 (0\%) & 0/143 (0) & 0/96 (0\%) & 0/175 (0) \\
\hline B. garinii & 9/192 (4.7\%) & 25/730 (3.4\%) & 6/96 (6.3\%) & $8 / 143(5.6 \%)$ & 15/96 (15.6\%) & 13/175 (7.4\%) \\
\hline B. Iusitaniae & 1/192 (0.5\%) & 2/730 (0.3\%) & 3/96 (3.1\%) & 0/143 (0) & 4/96 (4.2\%) & 5/175 (2.9\%) \\
\hline B. valaisiana & 7/192 (3.6\%) & 15/730 (2.1\%) & 3/96 (3.1\%) & $3 / 143(2.1 \%)$ & 7/96 (7.3\%) & 10/175 (5.7\%) \\
\hline \multicolumn{7}{|c|}{ Relapsing fever Borrelia } \\
\hline B. miyamotoi & 2/192 (1.0\%) & 0/730 (0) & $1 / 96(1.0 \%)$ & $1 / 143(0.7 \%)$ & $1 / 96(1.0 \%)$ & 0/175 (0) \\
\hline \multicolumn{7}{|c|}{ Not identified Borrelia } \\
\hline Borrelia spp. & 4/192 (2.1\%) & 0/730 (0) & $2 / 96(2.1 \%)$ & 0/143 (0) & 4/96 (4.2\%) & 0/175 (0) \\
\hline
\end{tabular}


[34]. In addition, female nymphs consume more blood than male nymphs [35], which results in a higher probability to acquire bacteria.

Five B. burgdorferi (s.l.) genospecies were identified, confirming the wide B. burgdorferi (s.l.) genospecies diversity in ticks from Spain. Borrelia garinii and $B$. valaisiana were the predominant genospecies, which in general agrees with most studies carried out in Spain $[18,21]$. Considering that $B$. garinii is mostly associated with neuroborreliosis, our results are in agreement with the high incidence of neurological symptoms observed in LB-infected patients from the same area of study [11, 36, 37]. Borrelia garinii was also identified in articular fluid from a patient with recurrent chronic arthritis on a knee [37]. An interesting finding was the occasional identification of B. burgdorferi (s.s.), even though it was reported as the predominant genospecies in some investigations performed in central and northern areas of Spain $[20,38]$. Although $B$. afzelii was previously identified in a skin biopsy from a patient with chronic erythema migrans in northwestern Spain [36], it is worth noting that the detection of this Borrelia genospecies was not frequent in ticks of the study area. In addition, its significance in other Spanish regions was also limited $[18,20,38]$. Nevertheless, it was reported as one of the most common Borrelia genospecies in some central and northern European countries [39]. In Europe, the differences in geographical distribution of most B. burgdorferi (s.l.) genospecies were reported to be mainly related to an adaptation to infect particular groups of vertebrates, such as mammalian or avian hosts, but not to both, limiting transmission between different host species [39, 40]. In fact, B. afzelii has been frequently associated with some rodents in Europe, and B. garinii with some bird populations, whereas B. burgdorferi (s.s.) appear to be less specialized [40].

The identified B. burgdorferi (s.l.) genospecies are considered amongst the most important causative agents of LB in Europe and Asia [41-43]. These results are consistent with investigations reporting I. ricinus, the major vector of the causative agents of $L B$, as the main and most abundant tick species in the vegetation of the North of the Iberian Peninsula [19-21, 29, 44] since areas with abundant rainfall, large vegetation cover, abundant wildlife populations and grazing domestic animals provide suitable habitats for that tick species [45]. In contrast, I. ricinus is a tick of minor importance in drier areas of central and southern Spain where other species, such as Hyalomma lusitanicum and Dermacentor marginatus, are predominant [38, 44]; for this reason most of LB cases in Spain have been diagnosed in the northern regions $[8,46,47]$.

Borrelia miyamotoi, related to the relapsing fever spirochete group, was only identified in four single ticks and in one I. ricinus male pool; this is the first report of this Borrelia species in free-living ticks from Spain. Despite the low percentages of $B$. miyamotoi detected in both the present study and in questing ticks from other European countries [48-51], it must be considered that this Borrelia species has been recently identified as a human pathogen, and it can be transmitted by all tick life stages [52]. Therefore, its presence should be taken into consideration in clinical patients.

Pooled testing is commonly used to estimate the presence of infection where the pathogen prevalence is likely low [53]. Our results also revealed that pooled testing is useful as a first approach when no epidemiological data on the pathogen is available in a particular area. In fact, higher numbers of B. burgdorferi (s.l.) genospecies were identified by means of pooled testing. Nevertheless, considering that pooled results underestimate the level of infection of a pathogen when its prevalence in a population is high, individual testing should be then performed in case of a significant number of positive pools.

\section{Conclusions}

A significant prevalence of B. burgdorferi (s.l.) genospecies was detected in questing ticks from northwestern Spain. This percentage of infection is similar to those found in some central and northern European countries, although a lower presence of B. afzelii and B. burgdorferi (s.s.) was detected in the study area. These results, together with the high incidence of LB previously diagnosed in humans from the same area in the last decade [11] and the high seroprevalence of B. burgdorferi (s.l.) in roe deer [12] confirm that Galicia is one of the most at-risk regions for acquiring LB in Spain. In addition, the first identification of $B$. miyamotoi in free-living ticks from Spain should be taken into consideration in clinical patients. Further longitudinal epidemiological studies must be carried out in order to assess a possible relation between the presence of different Borrelia genospecies and the increase of the incidence of LB in this area. This information will be useful for achieving a more detailed location of risk areas for acquiring LB, leading to the optimization of the diagnosis and treatment of the disease.

\section{Additional file}

Additional file 1: Table S1. Supplementary sequence information of all individual and pooled samples from Ixodes ricinus and identified as Borrelia burgdorferi (s.l.) or Borrelia miyamotoi. Borrelia burgdorferi (s.l.) isolates were characterized at both the flagellin (fla) gene and the $r r f A-r r / B$ intergenic spacer region (IGS); Borrelia miyamotoi isolates were characterized at the flagellin ( $f / a)$ and the glycerophosphodiester phosphodiesterase (GlpQ) genes. For each isolate and gene, the amplicon length and the closest matching sequences in GenBank are included. The GenBank number of unique partial sequences is also included. (DOCX $35 \mathrm{~kb}$ ) 


\section{Acknowledgements}

We would like to thank Eva Cabanelas for her invaluable help in collecting ticks.

\section{Funding}

This research was supported by a postdoctoral research grant (Banco de Santander, Spain) to PD and a predoctoral research grant (Xunta de Galicia, Spain) to SR and funds from the Program for consolidating and structuring competitive research groups (GRC2015/003, Xunta de Galicia, Spain).

\section{Availability of data and materials}

The data supporting the conclusions of this article are included within the article. A more detailed dataset used during the current study is available from the corresponding author upon reasonable request. Sequences were submitted to the GenBank database under the accession numbers MG245772-MG245790 and MG356949-MG356956.

\section{Authors' contributions}

PDB and PM established the final methods and design. MEVL, JMV and PD assisted with preliminary design of the study. PD, SR, APC and AP collected the ticks. SR and JMV identified the ticks. JLA and AB developed and performed the $\mathrm{GPCR}$. PD, SR, GF, CML and RP performed the rest of the experiments. CML conducted the statistical analysis. PD, JMV and JLA prepared the first paper draft. All authors read and approved the final manuscript.

\section{Ethics approval and consent to participate \\ Not applicable}

\section{Consent for publication}

Not applicable

\section{Competing interests}

The authors declare that they have no competing interests.

\section{Publisher's Note}

Springer Nature remains neutral with regard to jurisdictional claims in published maps and institutional affiliations.

\section{Author details \\ 'Departamento de Patología Animal (Grupo INVESAGA), Facultad de Veterinaria, Universidade de Santiago de Compostela, Lugo, Spain. 'Exopol, Zaragoza, Spain. 'Laboratorio de Vectores y enfermedades transmitidas, Facultad de Veterinaria, CENUR Litoral Norte, Universidad de la República, Salto, Uruguay. ${ }^{4}$ Servicio de Pediatría, Hospital Universitario Lucus Augusti, Lugo, Spain.}

\section{Received: 9 August 2017 Accepted: 6 December 2017}

Published online: 20 December 2017

\section{References}

1. Medlock JM, Hansford KM, Bormane A, Derdakova M, Estrada-Peña A, George JC, et al. Driving forces for changes in geographical distribution of Ixodes ricinus ticks in Europe. Parasit Vectors. 2013;6:1.

2. Franke J, Hildebrandt A, Dorn W. Exploring gaps in our knowledge on Lyme borreliosis spirochaetes - updates on complex heterogeneity, ecology, and pathogenicity. Ticks Tick Borne Dis. 2013:4:11-25.

3. Stanek G, Wormser GP, Gray J, Strle F. Lyme borreliosis. Lancet. 2012; 379:461-73.

4. Stanek G, Reiter M. The expanding Lyme Borrelia complex - clinical significance of genomic species? Clin Microbiol Infect. 2011;17:487-93.

5. Telford SR, Goethert HK, Molloy PJ, Berardi VP, Chowdri HR, Gugliotta JL, et al. Borrelia miyamotoi disease: neither Lyme disease nor relapsing fever. Clin Lab Med. 2015;35:867-82.

6. Krause PJ, Fish D, Narasimhan S, Barbour AG. Borrelia miyamotoi infection in nature and in humans. Clin Microbiol Infec. 2015;21:631-9.

7. Platonov AE, Karan LS, Kolyasnikova NM, Makhneva NA, Toporkova MG, Maleev W, et al. Humans infected with relapsing fever spirochete Borrelia miyamotoi. Russia Emerg Infect Dis. 2011;17:1816-23.
8. Anda P, Rodriguez I, Delaloma A, Fernandez MV, Lozano A. A serological survey and review of clinical Lyme borreliosis in Spain. Clin Infect Dis. 1993;16:310-9.

9. Escudero-Nieto R, Guerrero-Espejo A. Diseases produced by Borrelia. Enferm Infec Micr Cl. 2005;23:232-40.

10. Croche Santander B, Sánchez Carrión A, Campos E, Toro C, Marcos L, Vargas JC, et al. Fiebre recurrente transmitida por garrapatas en área rural del sur de España. An Pediatr (Barc). 2015;82:e73-7.

11. Vázquez-López ME, Pego-Reigosa R, Diez-Morrondo C, Castro-Gago M, Díaz $P$, Fernández $G$, et al. Epidemiology of Lyme disease in a healthcare area in north-west Spain. Gac Sanit. 2015;29:213-6.

12. Pato FJ, Panadero $R$, Vázquez L, López CM, Díaz P, Vázquez E, et al. Seroprevalence of Borrelia burgdorferi sensu lato in roe deer (Capreolus capreolus) from northwestern Spain. J Zoo Wildlife Med. 2013;44:660-5.

13. Pato FJ, Vázquez L, Díez-Baños N, López C, Sánchez-Andrade R, Fernández $\mathrm{G}$, et al. Gastrointestinal nematode infections in roe deer (Capreolus capreolus) from the NW of the Iberian peninsula: assessment of some risk factors. Vet Parasitol. 2013;196:136-42

14. Estrada-Peña A, Bouattour A, Camicas JL, Walker AR. Ticks of domestic animals in the Mediterranean region. A guide of identification of species. 1st ed. Zaragoza: University of Zaragoza Press; 2004.

15. Pérez-Eid C. Les tiques. Identification, biologie, importance médicale et vétérinaire. 1st ed. Paris: TEC \& DOC Lavoisier; 2007.

16. Barbour AG, Maupin GO, Teltow GJ, Carter CJ, Piesman J. Identification of an uncultivable Borrelia species in the hard tick Amblyomma americanum: possible agent of a Lyme disease-like illness. J Infect Dis. 1996;173:403-9.

17. Stromdahl EY, Williamson PC, Kollars TM, Evans SR, Barry RK, Vince MA, et al. Evidence of Borrelia lonestari DNA in Amblyomma americanum (Acari: Ixodidae) removed from humans. J Clin Microbiol. 2003:41:5557-62.

18. Escudero-Nieto R, Barral M, Perez A, Vitutia MM, Garcia-Perez AL, Jimenez S, et al. Molecular and pathogenic characterization of Borrelia burgdorferi sensu lato isolates from Spain. J Clin Microbiol. 2000;38:4026-33.

19. Barral M, Garcia-Perez AL, Juste RA, Hurtado A, Escudero R, Sellek RE, et al. Distribution of Borrelia burgdorferi sensu lato in Ixodes ricinus (Acari : Ixodidae) ticks from the Basque Country Spain. J Med Entomol. 2002;39:177-84.

20. Gil H, Barral M, Escudero R, Garcia-Perez AL, Anda P. Identification of a new Borrelia species among small mammals in areas of northern Spain where Lyme disease is endemic. Appl Environ Microb. 2005;71:1336-45.

21. Barandika JF, Hurtado A, Garcia-Sanmartin J, Juste RA, Anda P, Garcia-Perez AL. Prevalence of tick-borne zoonotic bacteria in questing adult ticks from northern Spain. Vector Borne Zoonotic Dis. 2008;8:829-35.

22. Derdáková M, Beati L, Pet'ko B, Stanko M, Fish D. Genetic variability within Borrelia burgdorferi sensu lato genospecies established by PCR-single-strand conformation polymorphism analysis of the rrfA-rrlB intergenic spacer in Ixodes ricinus ticks from the Czech Republic. Appl Environ Microbiol. 2003;69:509-16.

23. Hovius JW, de Wever B, Sohne M, Brouwer MC, Coumou J, Wagemakers A, et al. A case of meningoencephalitis by the relapsing fever spirochaete Borrelia miyamotoi in Europe. Lancet. 2013;382:658.

24. Pérez D, Kneubuehler Y, Rais O, Gern L. Seasonality of Ixodes ricinus ticks on vegetation and on rodents and Borrelia burgdorferi sensu lato genospecies diversity in two Lyme borreliosis-endemic areas in Switzerland. Vector Borne Zoonotic Dis. 2012;12:633-44.

25. Schwarz A, Hoenig V, Vavruskova Z, Grubhoffer L, Balczun C, Albring A, et al. Abundance of Ixodes ricinus and prevalence of Borrelia burgdorferi s.l. in the nature reserve Siebengebirge, Germany, in comparison to three former studies from 1978 onwards. Parasit Vectors. 2012;5:268.

26. Soleng A, Kjelland V. Borrelia burgdorferi sensu lato and Anaplasma phagocytophilum in Ixodes ricinus ticks in Bronnoysund in northern Norway. Ticks Tick Borne Dis. 2013;4:218-21.

27. Hönig V, Svec P, Halas P, Vavruskova Z, Tykalova H, Kilian P, et al. Ticks and tick-borne pathogens in south bohemia (Czech Republic) - spatial variability in Ixodes ricinus abundance, Borrelia burgdorferi and tick-borne encephalitis virus prevalence. Ticks Tick Borne Dis. 2015;6:559-67.

28. Vourc'h G, Abrial D, Bord S, Jacquot M, Masséglia S, Poux V, et al. Mapping human risk of infection with Borrelia burgdorferi sensu lato, the agent of Lyme borreliosis, in a periurban forest in France. Ticks Tick Borne Dis. 2016;7:644-52.

29. Ruíz-Fons F, Fernández-de-Mera IG, Acevedo P, Gortázar C, de la Fuente J. Factors driving the abundance of Ixodes ricinus ticks and the prevalence of zoonotic I. ricinus-borne pathogens in natural foci. Appl Environ Microb. 2012;78:2669-76. 
30. Wójcik-Fatla A, Zajac V, Sawczyn A, Sroka J, Cisak E, Dutkiewicz J. Infections and mixed infections with the selected species of Borrelia burgdorferi sensu lato complex in Ixodes ricinus ticks collected in eastern Poland: a significant increase in the course of 5 years. Exp Appl Acarol. 2016;68:197-212.

31. Lindgren E, TGT J. Lyme borreliosis in Europe: influences of climate and climate change, epidemiology, ecology and adaptation measures. EUR/04/ 5046250. Geneva: World Health Organization (WHO) Regional Office for Europe; 2006.

32. Jouda F, Perret JL, Gern L. Density of questing Ixodes ricinus nymphs and adults infected by Borrelia burgdorferi sensu lato in Switzerland: spatiotemporal pattern at a regional scale. Vector Borne Zoonotic Dis. 2004;4:23-32.

33. Kampen H, Rotzel DC, Kurtenbach K, Maier WA, Seitz HM. Substantial rise in the prevalence of Lyme borreliosis spirochetes in a region of western Germany over a 10-year period. Appl Environ Microb. 2004;70:1576-82.

34. Matuschka FR, Heiler M, Eiffert $H$, Fischer P, Lotter $H$, Spielman A. Diversionary role of hoofed game in the transmission of Lyme-disease spirochetes. Am J Trop Med Hyg. 1993;48:693-9.

35. Dusbábek F. Nymphal sexual dimorphism in the sheep tick /xodes ricinus (Acari: Ixodidae). Folia Parasitol. 1996;43:75-9.

36. Vázquez-López ME, Perez-Pacin R, Diez-Morrondo C, Díaz P, Castro-Gago M. Lyme disease in paediatrics. An Pediatr. 2016;84:234-5.

37. Vázquez-López ME, Díez-Morrondo C, Sánchez-Andrade A, Pego-Reigosa R, Díaz P, Castro-Gago M. Articular manifestations in patients with Lyme disease. Reumatol Clin. 2016;12:327-30.

38. Toledo A, Olmeda SA, Escudero R, Jado I, Valcárcel F, Casado-Nistal MA, et al. Tick-borne zoonotic bacteria in ticks collected from Central Spain. Am J Trop Med Hyg. 2009;81:67-74.

39. Estrada-Peña A, Ortega C, Sánchez N, DeSimone L, Sudre B, Suk JE, et al. Correlation of Borrelia burgdorferi sensu lato prevalence in questing Ixodes ricinus ticks with specific abiotic traits in the western Palearctic. Appl Environ Microb. 2011;77:3838-45.

40. Kurtenbach K, De Michelis S, Etti S, Schäfer SM, Sewell HS, Brade V, et al. Host association of Borrelia burgdorferi sensu lato - the key role of host complement. Trends Microbiol. 2002;10:74-9.

41. Biesiada G, Czepiel J, Lesniak MR, Garlicki A, Mach T. Lyme disease: review. Arch Med Sci. 2012;8:978-82.

42. Dehnert M, Fingerle V, Klier C, Talaska T, Schlaud M, Krause G, et al. Seropositivity of Lyme borreliosis and associated risk factors: a population-based study in children and adolescents in Germany (KiGGS). PLoS One. 2012;7

43. Kubiak K, Dzika E, Rowniak J, Dziedziech M, Dzisko J. Seroprevalence of Lyme disease and genospecies of Borrelia burgdorferi sensu lato in patients diagnosed with borreliosis in the province of Warmia-Masuria in northeastern Poland. Ann Agr Env Med. 2012;19:203-7.

44. Barandika JF, Olmeda SA, Casado-Nistal MA, Hurtado A, Juste RA, Valcarcel F, et al. Differences in questing tick species distribution between Atlantic and continental climate regions in Spain. J Med Entomol. 2011;48:13-9.

45. Estrada-Peña A, Martínez JM, Sánchez-Acedo C, Quílez J, Del Cacho E. Phenology of the tick, Ixodes ricinus, in its southern distribution range (central Spain). Med Vet Entomol. 2004;18:387-97.

46. Guerrero A. Lyme borreliosis in Spain. Enferm Infec Micr Cl. 2001;19:244-6

47. Portillo A, Santibanez S, Oteo JA. Lyme disease. Enferm Infec Micr Cl. 2014; 32(Suppl. 1):37-42.

48. Hansford KM, Fonville M, Jahfari S, Sprong H, Medlock JM. Borrelia miyamotoi in host-seeking Ixodes ricinus ticks in England. Epidemiol Infect. 2015;143:1079-87.

49. Nunes M, Parreira R, Lopes N, Maia C, Carreira T, Sousa C, et al. Molecular identification of Borrelia miyamotoi in Ixodes ricinus from Portugal. Vector Borne Zoonotic Dis. 2015;15:515-7.

50. Reiter M, Schoetta AM, Mueller A, Stockinger H, Stanek G. A newly established real-time PCR for detection of Borrelia miyamotoi in Ixodes ricinus ticks. Ticks Tick Borne Dis. 2015;6:303-8.

51. Sytykiewicz H, Karbowiak G, Chorostowska-Wynimko J, Szpechcinski A, Supergan-Marwicz M, Horbowicz M, et al. Coexistence of Borrelia burgdorferi s.l. genospecies within Ixodes ricinus ticks from central and eastern Poland. Acta Parasitol. 2015;60:654-61.

52. Wagemakers A, Staarink PJ, Sprong H, Hovius JWR. Borrelia miyamotoi: a widespread tick-borne relapsing fever spirochete. Trends Parasitol. 2015; 31:260-9.

53. Pritchard NA, Tebbs JM. Estimating disease prevalence using inverse binomial pooled testing. J Agric Biol Environ Stat. 2011;16:70-87.

\section{Submit your next manuscript to BioMed Central and we will help you at every step:}

- We accept pre-submission inquiries

- Our selector tool helps you to find the most relevant journal

- We provide round the clock customer support

- Convenient online submission

- Thorough peer review

- Inclusion in PubMed and all major indexing services

- Maximum visibility for your research

Submit your manuscript at www.biomedcentral.com/submit 